\title{
A Calculation Method of the Artwork Portfolio Investment Risk Based on the Hedonic Model
}

\author{
Wang Zhaoyan and Feng Junwen
}

\begin{abstract}
A boom in the art market in recent decades heightened investor interest and revived analysis by finance scholars. The primary focus of the finance of art literature is on the yield and risk of art as an investment. Nowadays, the Hedonic index method had gained a lot of achievements in the artwork pricing and investment, but has not yet been introduced to the study of artwork portfolio investment risk. This paper proposed a calculation method of the artwork portfolio investment risk based on the Hedonic model. The current situation and characteristics of the artwork investment market were analyzed. An example about the Chinese artist painting artwork portfolio showed the practicability and effectiveness of the proposed method.
\end{abstract}

Index Terms-Artwork portfolio, investment risk, hedonic model.

\section{INTRODUCTION}

With the continuous rising of the artwork investment boom, the artwork portfolio selection problem caused more and more attention from scholars. According to the investment theory, the size of the portfolio investment risk determined the investment choice behavior [1]. However, a few researches paid attention to the artwork portfolio investment risk. Therefore, the problems of how to quantitatively analyze the expected yield and investment risk of the artwork portfolio needed to be resolved quickly.

In recent years, the research of artwork portfolio investment risk mainly adopted the repeated transactions regression model. Stein analyzed the risk-reward profile of the American and British's oil paintings in the period from 1946 to 1968 [2]. He adopted the average price model to establish the oil price index, and divided the artwork investment income into two parts: a part from the art aesthetic value and the other part from the opportunity cost of the artwork investment. Goetzmann studied 3329 groups of oil painting price data of United States from 1720 to 1990 based on the repeated trading regression model [3]. In addition, he considered the correlation of the Profitability, risk, stock and bond of artwork market from 1720 to 1990.Pesando adopted the repeated trading regression model to analyze the Goldman annual art prices data from 1977 to 1992 [4]. He pointed that the yield of high-grade artworks are lower than the low-grade artworks. Tucker et al. studied the role of artwork in a portfolio and pointed that the introduction of artwork can effectively improve the quality of the portfolio [5]. Andrew et

Manuscript received December 25, 2014; revised April 15, 2015.

The authors are with the School of Economics and Management, Nanjing University of Science and Technology, Nanjing, 210094 China (e-mail: zywang_2014@163.com,jwfeng99@163.com). al proposed that different kinds of artwork market and financial market have cooperative relations and the artwork portfolio can reduce risk no matter a long or short time [6]. Campbell studied the correlation of the Mei Moses index, S\&P500 index and American treasury index from 1875 to 2002, and pointed out that there is no causality between the stock market and artwork market [7]. After a few years, Campbell broadened the research scope and studied the average yields, variance and correlation of the art 100 index of American artwork market, the United States 100 index, the Braitain100 index and the of artwork market overall index [8]. Although the repeated transactions regression model is simple and easy to calculate, it has a lot of limitations. Such as: (1) The repeated sales regression model required that the same artwork have multiple transactions data. However, the same artwork cannot be traded frequently by investors, which make the repeated sales regression model cannot be used in the artwork with a few transactions; (2) The artwork prices usually were decided by many factors, and the repeated sales regression model did not consider the influence of those art prices factors on the yield and risk of portfolio; (3) Since the expected yield and investment risk of artwork portfolio were calculated by the repeated sales regression model, its accuracy were influenced by the number of artwork data. The yields and investment risks may not be accurate with few artwork data.

Court first introduced a Hedonic price index method, which also known as the Hedonic regressive method. The Hedonic method analyzed the influence of several factors on the price, and avoided the limitations of sample data and subjective deviation [9]. It had a higher scientific and accuracy and was the mainstream method of precision evaluation. Biey et al introduced the price index method into the pricing research of contemporary artworks [10]. He constructed the artwork prices model by using the properties, which influence the size and material of the art prices. Goetzmann and Ursprung considered the influence of the macro factors, such as prices of financial assets and income levels, and the micro factors , such as artwork size and creative age, on the artwork assets yield [11], [12]. Renneboog et al calculated the Russian artwork price index based on the Hedonic price index and pointed that there is a huge difference of return on investment between different types of artwork [13]. Taylor constructed the price index of Australian aboriginal artwork by Hedonic price index and found that the high artwork yield is about $2 \%$ less than other artworks [14]. In addition, Renneboog et al analyzed and improved the Hedonic index method and applied it into the pricing, investment, and analysis of artwork market [15]-[18]. Nowadays, the Hedonic index method had gained a lot of achievements in the artwork pricing and investment. It has not yet been introduced to the study of 
artwork portfolio investment risk.

To solve the existing investment risk problems of artwork portfolio, the paper proposed a calculation method of the artwork portfolio investment risk based on the Hedonic model. This method constructed the Chinese artwork price model by the Hedonic price method and given the 6-months yield of artwork portfolio. Then, the paper analyzed the correlation of different artwork assets and calculated the investment risk of art portfolio.

\section{The Proposed Calculation Method of the ARTWORK PORTFOLIO INVESTMENT RISK}

\section{A. The Construction of Artwork Price Model}

In the study of the artwork price model, the classic Hedonic regressive model is a semi-log model [15], which can be expressed as following:

$$
\ln P_{k t}=\alpha+\sum_{i=1}^{I} \beta_{i} X_{i k t}+\sum_{j=1}^{J} \gamma_{j} D_{j k t}+\varepsilon_{k t}
$$

where $P_{k t}$ is the $k^{\text {th }}$ artwork at $t$ sample, $X_{i k t}$ is the $i^{\text {th }}$ quantitative factor, which effect the price of the $k^{\text {th }}$ artwork at $t$ sample,$D_{j k t}$ is the $j^{\text {th }}$ qualitative factor, which effect the price of the $k^{\text {th }}$ artwork at $t$ sample, $\alpha$ is a constant, $\beta_{m}$ and $\gamma_{t}$ are the coefficients of the quantitative factor $X_{i k t}$ and the qualitative factor $D_{j k t}$ respectively, $\varepsilon_{k t}$ is random error.

In order to get better statistical properties and more accurate calculations, the paper applied the following double-log model to analyze the Chinese artwork price:

$$
\ln P_{k t}=\alpha+\sum_{i=1}^{I} \beta_{i} \ln X_{i k t}+\sum_{j=1}^{J} \gamma_{j} D_{j k t}+\varepsilon_{k t}
$$

The above double-log Hedonic regressive model has a lot of advantages, such as: Since the artwork auction price always has a bigger deviation, the double-log model can effectively reduce or eliminate the deviation; the elasticity relationship between variables can be clearly shown by the coefficients of the double-log model; the double-log model has a better goodness-of-fit than half-log model.

Though the estimation of the experimental data, we can get the following fitting model function:

$$
\ln \hat{P}_{k t}=\hat{\alpha}+\sum_{i=1}^{I} \hat{\beta}_{i} \ln X_{i k t}+\sum_{j=1}^{J} \hat{\gamma}_{j} D_{k t}
$$

where $\hat{P}_{k t}$ is the estimated price of the $k^{\text {th }}$ artwork at $t$ sample, $\hat{\alpha}$ is a estimated constant, $\hat{\beta}_{m}$ and $\hat{\gamma}_{t}$ are the estimated coefficients of the quantitative factor $X_{i k t}$ and the qualitative factor $D_{j k t}$ respectively.

\section{B. The Assumptions for the Problems of Artwork Portfolio Selection}

According to the basic assumption of Markowitz portfolio model, the paper considered the characteristics in the study of artwork portfolio selection, and made the following assumptions for the problems of artwork portfolio selection:

1) The number of artworks in the artwork investment market is more than two, i.e. $k \geq 2$;

2) Since the artwork investors are risk aversion, they will chose the lowest risk of portfolio in the case of that the income is enough to meet investors expect;

3) The investors only care about the mean value, variance of risk assets and the covariance of different assets in the selection process of the optimal portfolio.

\section{The Calculation of the Yield and Investment Risk of the Artwork Portfolio Based on the Markowitz Model}

\section{1) The 6-Month Yield Estimation of an Artwork}

Since the interval of two adjacent sale season of artwork is about 6-month, the artwork yield is calculated once about 6-month. The calculation function of the artwork 6-month yield can be expressed as follows:

$$
r_{k, t}=\left\{\begin{array}{l}
\frac{P_{k, t}-P_{k, t-1}-Q_{k, t}}{P_{k, t-1}} \times(100-\psi) \%, r_{k, t}>0 \\
\frac{P_{k, t}-P_{k, t-1}-Q_{k, t}}{P_{k, t-1}} \times 100 \%, r_{k, t}>0
\end{array}\right.
$$

where $r_{k, t}$ is the 6-month yield of the $k^{\text {th }}$ artwork at $t^{\text {th }}$ 6-month, $P_{k, t}$ is the price of the $k^{\text {th }}$ artwork at $t^{\text {th }}$ 6-month, $P_{k, t-1}$ is the price of the $k^{\text {th }}$ artwork at $t-1^{\text {th }}$ 6-month, $Q_{k, t}$ is the auction commission of the $k^{\text {th }}$ artwork at $t^{\text {th }}$ 6-month, $\psi$ is the individual income tax.

Through the analysis of the 6-month yield estimation of an artwork, we found that the 6-month yield estimation of an artwork has different calculation method in different auction period:

When $t=1$, the calculation function of the artwork 6-month yield can be expressed as follows:

$$
\hat{r}_{k, 1}=\left\{\begin{array}{l}
\frac{\hat{P}_{k, 1}-P_{k, 0}-Q_{k, 1}}{P_{k, 0}} \times(100-\psi) \%, \hat{r}_{k, 1}>0 \\
\frac{\hat{P}_{k, 1}-P_{k, 0}-Q_{k, 1}}{P_{k, 0}} \times 100 \%, \hat{r}_{k, 1}>0
\end{array}\right.
$$

where $\hat{r}_{k, 1}$ is the 6-month yield estimation of the $k^{\text {th }}$ artwork at the first 6-month, $\hat{P}_{k, 1}$ is the price of the $k^{\text {th }}$ artwork at the first 6-month, $\hat{P}_{k, 0}$ is the initial price of the $k^{\text {th }}$ artwork.

When $t \geq 2$, the calculation function of the artwork 6-month yield can be expressed as follows:

$$
\hat{r}_{k, t}=\left\{\begin{array}{l}
\frac{\hat{P}_{k, t}-\hat{P}_{k, t-1}-Q_{k, t}}{\hat{P}_{k, t-1}} \times(100-\psi) \%, \hat{r}_{\mathrm{k}, t}>0 \\
\frac{\hat{P}_{k, t}-\hat{P}_{k, t-1}-Q_{k, t}}{\hat{P}_{k, t-1}} \times 100 \%, \hat{r}_{k, t}>0
\end{array}\right.
$$

where $\hat{r}_{k, t}$ is the 6-month yield estimation of the $k^{\text {th }}$ artwork at $t^{\text {th }} 6$-month, $P_{k, t}$ is the price of the $k^{\text {th }}$ artwork at $t^{\text {th }}$ 6-month, $P_{k, t-1}$ is the price of the $k^{\text {th }}$ artwork at $t-1^{\text {th }}$ 6-month . 
According to the Eq.(5) and Eq.(6), we can get the expected 6-month yield estimation and variance estimation of an artwork:

$$
\begin{gathered}
\hat{\mu}_{k}=\frac{1}{T} \sum_{t=1}^{T} \hat{r}_{k, t} \\
\hat{\sigma}_{k}^{2}=\frac{1}{T} \sum_{t=1}^{T}\left(\hat{r}_{k, t}-\hat{\mu}_{k}\right)^{2}
\end{gathered}
$$

where $\hat{\mu}_{k}$ is the expected 6-month yield estimation of the $k^{\text {th }}$ artwork, $\hat{\sigma}_{k}^{2}$ is the variance estimation of the $k^{\text {th }}$ artwork $\mathrm{k}$, $T$ is the total 6-month number of the $k^{\text {th }}$ artwork investment.

\section{2) The estimation of the expected yield and investment} risk of the artwork portfolio

The yield of artwork portfolio is obtained by the weighted average of all artworks yield in the portfolio, and the investment risk is determined by the covariance of all artworks yield. For an artwork portfolio $M$, which contained $K$ artworks, the expected yield and investment risk can be expressed as:

$$
\begin{gathered}
\mu_{M}=\sum_{k=1}^{K} w_{k} \mu_{k} \\
\sigma_{M}^{2}=\sum_{p=1}^{K} \sum_{q=1}^{K} w_{p} w_{q} \sigma_{p} \sigma_{q} \rho_{p q}
\end{gathered}
$$

where $\mu_{M}$ is the expected yield of portfolio $M, w_{k}$ is the proportion of artwork $k$ in the portfolio $M, \sigma_{M}^{2}$ is the investment risk, $\sigma_{p}$ and $\sigma_{q}$ are standard deviation of the price of artwork $p$ and artwork $q$ respectively, $\rho_{p q}$ is the correlation coefficient of the price of artwork $p$ and artwork $q$.

According to the Eq.(9) and Eq.(10), we can get the expected yield estimation and investment risk estimation of the artwork portfolio $M$ :

$$
\begin{gathered}
\hat{\mu}_{M}=\sum_{k=1}^{K} w_{k} \hat{\mu}_{k} \\
\hat{\sigma}_{M}^{2}=\sum_{p=1}^{K} \sum_{q=1}^{K} w_{p} w_{q} \hat{\sigma}_{p} \hat{\sigma}_{q} \hat{\rho}_{p q}
\end{gathered}
$$

where $\hat{\mu}_{M}$ is the expected yield estimation of portfolio $M$, $\hat{\sigma}_{M}^{2}$ is the investment risk estimation, $\hat{\sigma}_{p}$ and $\hat{\sigma}_{q}$ are standard deviation of the estimated price of artwork $p$ and artwork $q$ respectively, $\hat{\rho}_{p q}$ is the correlation coefficient of the estimated price of artwork $p$ and artwork $q$.

\section{3) The steps of the proposed method}

The paper proposed a calculation method of the artwork portfolio investment risk based on the Hedonic model. The specific steps are as follows:

Step1: Calculate the 6-month price of each artwork. The influence factors are analyzed and the artwork price function is fitted by the double-log Hedonic model;

Step2: Calculate the 6-month expected yield estimation and variance of each artwork;

Step3: Calculate the 6-month expected yield estimation of each artwork portfolio and obtain the investment risk estimation.

\section{THE EXAMPLE ANALYSIS}

Two groups of Chinese painting artwork portfolio were chosen as an example to illustrate the effective of the proposed method in Table I. The artists of those two groups of Chinese painting artwork portfolio were Huang yong-yu $(\mathrm{H})$ and Wu qing-xia (W). The artwork data were collected from the 2014 spring auction market. In order to make the calculation process simple and clear, the paper made the following assumptions: (1) Investors can buy every artwork at the price of the 2014 spring auction market; (2) Investors expected that the average annual growth of GDP is $7.8 \%$ over the next five years; (3) Since the commission of different auction company or individual had bigger difference, the paper assumed that the commission is zero, i.e. $Q_{k, t}=0$ in the process of auction.

TABLE I: ART PORTFOLIO

\begin{tabular}{cll}
\hline \hline \multirow{2}{*}{ Number } & \multicolumn{2}{c}{ TABLE I: ART PORTFOLIO } \\
\cline { 2 - 3 } & Artists \& Artwork & \\
\hline \multirow{2}{*}{ A } & Gyong yong-yu (H) & Wu qing-xia (W) \\
& & $\begin{array}{l}\text { Pond of Lotus (W1) } \\
\text { Dongshan concert (W2) }\end{array}$ \\
\hline \multirow{2}{*}{ B } & Gyosho (H1) & $\begin{array}{l}\text { Dongshan concert W2) } \\
\text { View waterfall (W3) } \\
\end{array}$ \\
\hline \hline
\end{tabular}

\section{A. The Influence Factors Analysis}

Since the data of Chinese painting artwork market is easy to obtain, the paper divided the influence factors into quantitative and qualitative factors on the basis of drawing lessons from the past art field experts. The quantitative and qualitative factors of Chinese painting artwork market were shown in Table II and Table III.

TABLE II: THE QUANTITATIVE FACTORS OF PAINTING ARTWORK

\begin{tabular}{ll}
\hline \hline Quantitative & $\operatorname{Area}\left(s_{1}\right.$, Unit:Meter $)$ \\
\cline { 2 - 2 } factors & $\operatorname{GDP}\left(s_{2}\right.$, Unit:Billion $)$ \\
\hline \hline
\end{tabular}

\section{B. The Model Construction and the Data Analysis}

Using the double-log Hedonic regression model in Eq.(3) to fit the collected data, we can get the following two price functions of those two artwork portfolio:

$$
\begin{aligned}
\ln \hat{P}_{H}= & -18.4262+5.9254 \ln s_{1}+1.8352 \ln s_{2}-6.9466 a_{2} \\
- & 11.4796 a_{3}-5.1710 b+44.5553 c_{1}+6.4209 c_{2} \\
& -7.9407 c_{4}+19.3520 d_{2}-5.2425 d_{3}-12.5191 d_{4} \\
- & 20.0166 d_{5} \\
\ln \hat{P}_{W}= & -4.1374+1.4230 \ln s_{1}+0.6669 \ln s_{2}-2.2645 a_{1} \\
& +0.0379 a_{2}+2.1054 a_{3}-3.1435 b+0.1861 c_{2} \\
& -4.3235 c_{4}+4.7432 d_{1}-2.7979 d_{2}-1.7159 d_{3} \\
& -0.0900 d_{4}-4.4569 d_{5}
\end{aligned}
$$

where $\hat{P}_{H}$ is the estimated price of Huang yong-yu artwork and $\hat{P}_{W}$ is the estimated price of Wu qing-xia artwork. 
The data of each artwork price and influence factors in table 1-3 were collected from Yachang artwork monitoring center. The 6-month price of each artwork can be obtained from Eq.(13) and Eq.(14). Then, the 6-monthe expected yield estimation and investment risk estimation of each artwork can be calculated by Eq.(7) and Eq.(8). Finally, applying Eq.(11) and Eq.(12) to calculate the investment risk of each artwork portfolio. The results of the example were shown in Table IV.

TABLE III: THE QUALITATIVE FACTORS OF PAINTING ARTWORK

\begin{tabular}{|c|c|c|c|c|}
\hline & & & Yes & No \\
\hline \multirow{15}{*}{$\begin{array}{l}\text { Qualitative } \\
\text { factors }\end{array}$} & \multirow{4}{*}{$\begin{array}{l}\text { Painting } \\
\text { type }\end{array}$} & Album /Layout ( $\left.a_{1}\right)$ & 1 & 0 \\
\hline & & Kyoshin/Cloth cover $\left(a_{2}\right)$ & 1 & 0 \\
\hline & & Vertical shaft /Paper $\left(a_{3}\right)$ & 1 & 0 \\
\hline & & Picture frame/Board $\left(a_{4}\right)$ & 1 & 0 \\
\hline & $\begin{array}{l}\text { Auction } \\
\text { season }\end{array}$ & Spring $(b)$ & 1 & 0 \\
\hline & \multirow{5}{*}{$\begin{array}{l}\text { Auction } \\
\text { address }\end{array}$} & Hong Kong $\left(c_{1}\right)$ & 1 & 0 \\
\hline & & Beijing $\left(c_{2}\right)$ & 1 & 0 \\
\hline & & Shanghai $\left(c_{3}\right)$ & 1 & 0 \\
\hline & & Hangzhou $\left(c_{4}\right)$ & 1 & 0 \\
\hline & & Guangzhou $\left(c_{5}\right)$ & 1 & 0 \\
\hline & \multirow{5}{*}{$\begin{array}{l}\text { Creative } \\
\text { time }\end{array}$} & $50 / 60$ 's $\left(d_{1}\right)$ & 1 & 0 \\
\hline & & 70 's $\left(d_{2}\right)$ & 1 & 0 \\
\hline & & $80^{\prime} \mathrm{s}\left(d_{3}\right)$ & 1 & 0 \\
\hline & & 90 's $\left(d_{4}\right)$ & 1 & 0 \\
\hline & & After $2000\left(d_{5}\right)$ & 1 & 0 \\
\hline
\end{tabular}

TABLE IV: THE ARTWORK PORTFOLIO INVESTMENT RISK

\begin{tabular}{cccc}
\hline \hline Artwork portfolio & $\begin{array}{c}\text { Total investment } \\
\text { amount (Million) }\end{array}$ & $\begin{array}{c}\text { Expected } \\
\text { yields (\%) }\end{array}$ & $\begin{array}{l}\text { Investment } \\
\text { risk }\end{array}$ \\
\hline $\mathrm{A}$ & 104.6500 & 4.8335 & 4.0017 \\
\hline $\mathrm{B}$ & 113.8500 & 4.8248 & 4.6598 \\
\hline \hline
\end{tabular}

It can be seen from Table IV, the expected yield of artwork portfolio A and artwork portfolio B almost are the same, but the total investment amount and investment risk of artwork portfolio A are all lower than art portfolio B. The investors will choose art portfolio A as the investment object if they consider that the risk aversion and the investment amount are very important.

\section{CONCLUSION}

The paper analyzed the existing investment risk problems of artwork portfolio, and built the artwork price model based on the Hedonic price index method. The 6-month yield of artwork portfolio was given and the investment risk was calculated based on the artwork price model. The proposed method introduced the Hedonic price index method to the investment risk research of artwork portfolio, and analyzed the influence of different factor on the artwork price. This method was not only to solve the problem of $\mathrm{f}$ transaction data, but also to improve the accuracy of 6-month expected yield and variance of artwork. Two examples of Chinese painting art portfolio showed that the method is practical and effective.

\section{REFERENCES}

[1] Z. Bodie, Investments, New York: Tata McGraw-Hill Education, 2009.

[2] J. P. Stein, "The monetary appreciation of paintings," Journal of Political Economy, vol. 5, pp. 1021-1035, 1977.

[3] W. N. Goetzmann, "Accounting for taste: Art and the financial markets over three centuries," American Economic Review, vol. 83, pp. 1370-1376, 1993.

[4] J. E. Pesando, "Art as an investment: The market for modern prints," American Economic Review, vol. 83, pp. 1075-1089, 1993.

[5] M. Tucker, M. Hlawischka, and J. Pierne, "Art as an investment: A portfolio allocation analysis," Managerial Finance, vol. 21, pp. 16-25, 1995.

[6] W. Andrew and H. Higgs, "Financial returns and price determinants in the Australian art market 1973-2003," Economic Record, vol. 81, pp. 113-126, 2005.

[7] R. Campbell, "Art as an alternative asset class," Journal of Alternative Investments, vol. 17, pp. 50-63, 2005.

[8] R. Campbell, "Art as a financial investment," Journal of Alternative Investments, vol. 20, pp. 64-81, 2008.

[9] A. T. Court, "Hedonic price indexes with automotive examples," The Dinamics of Automobile Demand, pp. 99-117, 1939.

[10] M. L. Biey and R. Zanola, "The sculpture market: An adjacent year regression index," Journal of Cultural Economics, vol. 26, pp. 65-78, 2002.

[11] W. N. Goetzmann, L. Renneboog, and C. Spaenjers, "Art and money," American Economics Review, vol. 101, pp. 222-226, 2011.

[12] H. W. Ursprung and C. Wiermann, "Reputation, price and death: An empirical analysis of art price formation," Economic Inquiry, vol. 49, pp. 697-715, 2011.

[13] L. Renneboog and C. Spaenjers, "The iconic boom in modern Russian art," The Journal of Alternative Investments, vol. 13, pp. 67-80, 2011

[14] D. Taylor and L. Coleman, "Price determinates of aboriginal art, and its role as an alternative asset class," Journal of Banking \& Finance, vol. 35, pp. 1519-1529, 2011.

[15] L. Renneboog and C. Spaenjers, "Buying beauty: On prices and returns in the art market," Management Science, vol. 59, pp. 36-53, 2013.

[16] A. Collins, A. Scorcu, and R. Zanola, "Reconsidering hedonic art price indexes," Economics Letters, vol. 104, pp. 57-60, 2009.

[17] F. Y. R. P. Bocart and C. M. Hafner, "Volatility of price indices for heterogeneous goods with applications to the fine art market," Journal of Applied Econometrics, 2013.

[18] E. Dimson and C. Spaenjers, "Ex post: The investment performance of collectible stamps," Journal of Financial Economics, vol. 100, pp. 443-458, 2011.

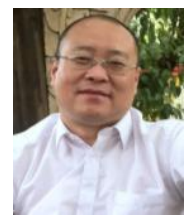

Wang Zhaoyan was born in May 1977. He finished his master studies at Hunan University of Technology in 2002. He works as a senior artist, a craftsman and a master supervisor at the School of Economics, Peking University from 2006. Since 2012 he studies at the School of Economics and Management, Nanjing University of Science and Technology as a PhD student. His research interests are connected with artwork investment and risk management.

Feng Junwen was born in March 1960. He finished his master studies at the Department of Systems Engineering, Nanjing University of Science and Technology in 1987. In 1990 he finished his master studies at the Department of Project Management and Systems Engineering, Beijing University of Aeronautics and Astronautics. From 2000, He works as a professor and a PhD supervisor at the School of Economics and Management, Nanjing University of Science and Technology. He worked in the University of Washington and University of Kansas as academic visitor from 2005 to2010. His research interests are connected with project management, systems engineering, risk management, operations research and multi-objective decision. 